\title{
Risk Factors and Epidemiological Profile of Multi-Resistant Bacteria in Nosocomial Pneumonia
}

\author{
I. Karrati ${ }^{1 *}$, L. Ait Said ${ }^{1}$, M. Diakité ${ }^{1}$, A. Hilmi ${ }^{1}$, M. Khallouki ${ }^{2}$, K. Zahlane ${ }^{1}$
}

${ }^{1}$ Microbiology Laboratory, Ibn Tofail Hospital, CHU Mohamed 6 Marrakech, FMPM, Rue Abdelouahab Derraq, Marrakech 40000, Morocco

${ }^{2}$ Resuscitation Service, Ibn Tofail Hospital, CHU Mohamed 6 Marrakech, FMPM, Rue Abdelouahab Derraq, Marrakech 40000, Morocco

DOI: $10.36347 /$ sjams.2022.v10i01.011

| Received: 18.11.2021 | Accepted: 24.12.2021 | Published: 17.01.2022

*Corresponding author: I. Karrati

Abstract

Original Research Article

Nosocomial pneumonia (NP) is the second most common cause of nosocomial infection in the intensive care unit (ICU). They pose significant diagnostic, therapeutic and economic problems and increase the risk of death by increasing the length of stay in the ICU. The emergence of resistance to last-resort antibiotics in therapy defines multiresistant bacteria (MRB). Our work is a retrospective descriptive and analytical study spread over one year (from 1 to 30 December 2019) which focused on patients admitted to the intensive care unit of Ibn Tofail Hospital in Marrakech and who presented with a nosocomial MRB pneumopathy. BMRs were isolated in $38 \%$ of cases. Imipenem-resistant Acinetobacter baumanii (IRBA) was the most isolated multi-resistant pathogen. The high level of co-resistance to other antibiotic families leaves little room for treatment. The risk factors found to play a role in the acquisition of BMR NPs were: age between 36 and 45 years, length of hospital stay between 10 and 20 days, presence of comorbidity, radiological picture suggestive of NPs and broad spectrum antibiotic therapy. Measures to prevent NP are increasingly being adopted as an indicator of quality of care in intensive care units worldwide. Thus, reducing the incidence of NP and MRB should be a goal for all hospitals. In our context, measures to control MRBs must be reinforced by hygiene measures and precautions, in particular the identification of infected or colonised patients, the technical and geographical isolation of patients carrying MRBs and the use of appropriate treatment. Thus, regular epidemiological surveillance is necessary to guide management and define an adequate prevention strategy adapted to the context.

Keywords: Risk factors - Nosocomial pneumonia - Antibiotic resistance - Multi-resistant bacteria.

Copyright $(\mathcal{2 0 2 2}$ The Author(s): This is an open-access article distributed under the terms of the Creative Commons Attribution 4.0 International License (CC BY-NC 4.0) which permits unrestricted use, distribution, and reproduction in any medium for non-commercial use provided the original author and source are credited.

\section{INTRODUCTION}

Nosocomial pneumonia (NP) is the second most common hospital-acquired infection, and the most common in the ICU.

Despite progress in antibiotic therapy, substitution techniques and the implementation of preventive measures, NP still represents one of the major public health problems responsible for a very high morbidity and mortality rate and a high cost of care [1]. Therefore, in this work, we will study the frequency and involvement of multi-resistant bacteria (MRB) in NPs and analyse the risk factors for the acquisition of NPs with MRBs.

\section{Material And Methods}

This is a retrospective study conducted at the microbiology laboratory in collaboration with the resuscitation - anaesthesia department of Ibn Tofail Hospital in Marrakech over a period of one year from 1 January to 31 December 2019.

In this study, the patients included were adults presenting signs of NP after $48 \mathrm{~h}$ of hospitalization in the intensive care unit, and having benefited from bacteriological respiratory sampling by endo-tracheal aspiration (ETA), by protected distal sampling (PDS) or by bronchoalveolar lavage (BAL) Each sample was systematically examined macroscopically, microscopically in the fresh state and after gram staining, cultured, identified and finally tested for antibiotic sensitivity.

Statistical analysis was performed using SPSS version 20.0 
I. Karrati et al; Sch J App Med Sci, Jan, 2022; 10(1): 72-78

\section{RESULTS}

\section{1- Epidemiological profile of multi-resistant bacteria} (MRB)

Out of 202 samples received, 233 bacterial species were isolated of which 89 were MDR. Imipenem-resistant Acinetobacter baumannii (IRBA) was the most frequently isolated, followed by extendedspectrum beta-lactamase (ESBL)-producing Enterobacteriaceae and carbapenemase (CPE)producing Enterobacteriaceae. Methicillin-resistant Staphylococcus aureus (MRSA) and imipenem-resistant Pseudomonas aeruginosa (IRAP) were found at low levels. No glycopeptide-resistant enterococci were found (Figure 1).

The majority of Acinetotobacter baumannii isolates were ABRI (95.6\%). Enterobacteriaceae ESBL and EPC were found in $1 / 4$ of the cases. MRSA and IRAP had low rates compared to Staphylococcus aureus and Pseudomonas aeruginosa respectively (Figure 2). Of the ESBL and EPC Enterobacteriaceae found,
Klebsiella pneumoniae accounted for approximately half, while E.coli and Citrobacter shared the remaining $25 \%$ of cases (Figure 3 ).

Concerning the co-resistance of MRB to antibiotics, our study showed a very high rate of resistance to aminoglycosides, ciprofloxacin and cotrimoxazole, except for ESBL and EPC Enterobacteriaceae which are more sensitive to amikacin. Colistin is still the only sensitive therapeutic tool for the treatment of NPs (Figure 4).

Concerning the distribution of the main enterobacteria according to the degree of resistance: Klebsiella pneumoniae and E.coli were found to be susceptible or to have a low level penicillinase in $10.5 \%$ and $37 \%$ of cases respectively. No Proteus spp or Enterobacter spp strains were identified as ESBL or EPC enterobacteria. In our series, $100 \%$ of Proteus spp and $75 \%$ of Enterobacter spp were susceptible or showed a low level penicillinase (Figure 5).

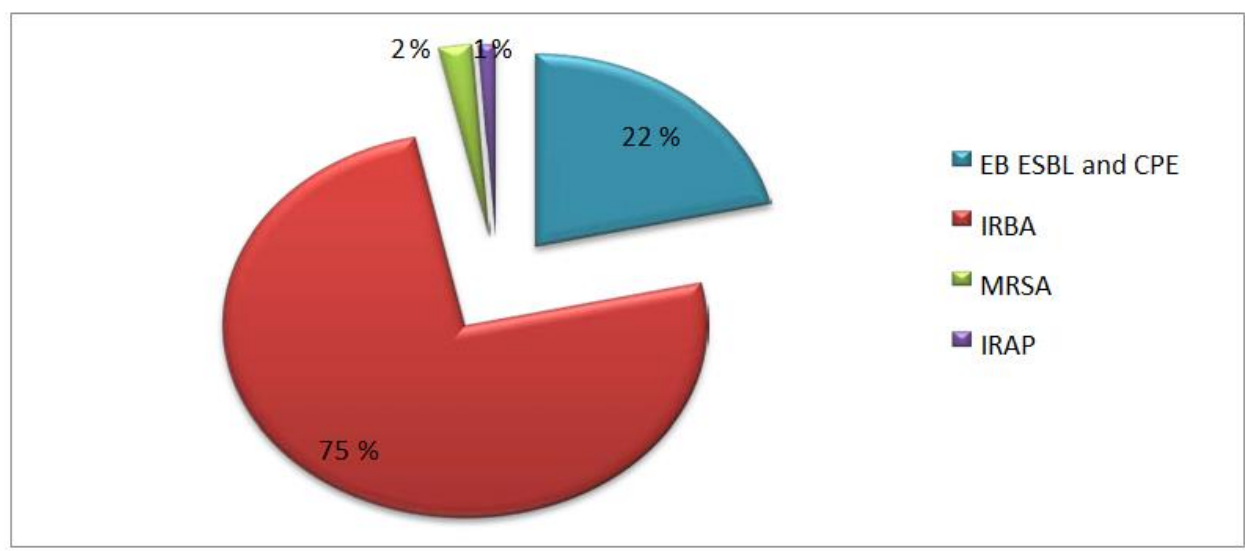

Figure 1: Nature of the MDRs isolated

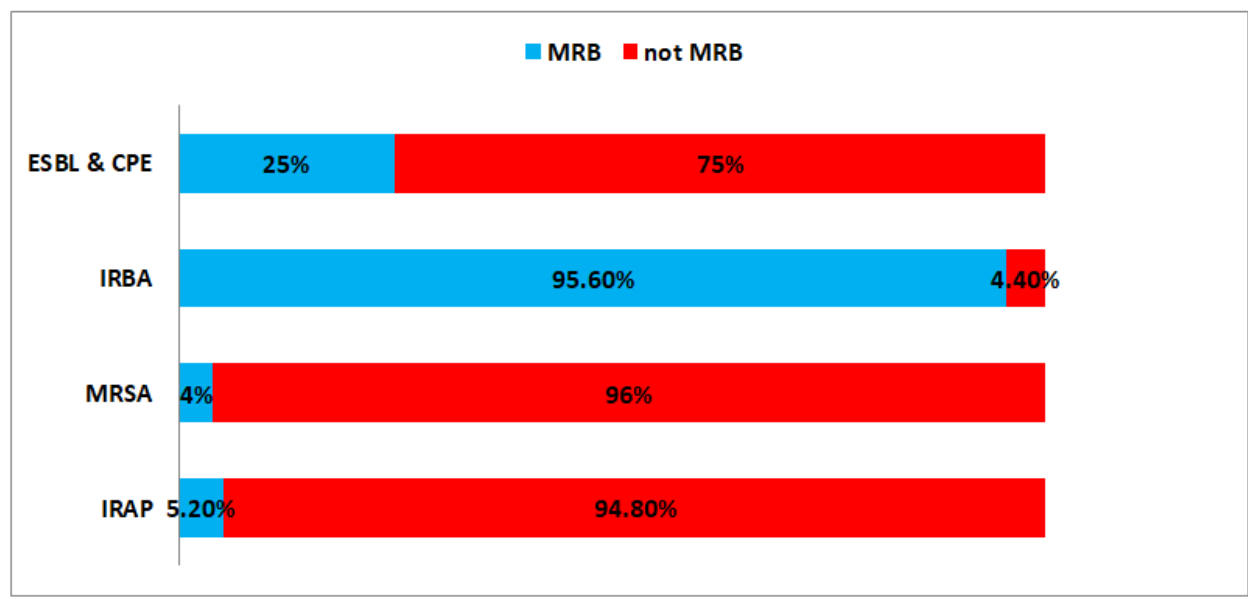

Figure 2: Multidrug-resistance rates within species 


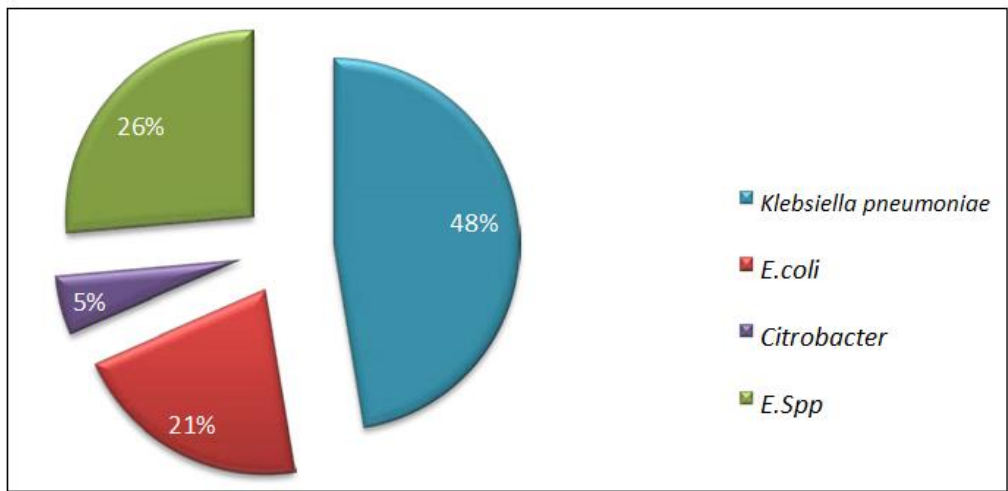

Figure 3: Species distribution of Enterobacteriaceae ESBL and EPC

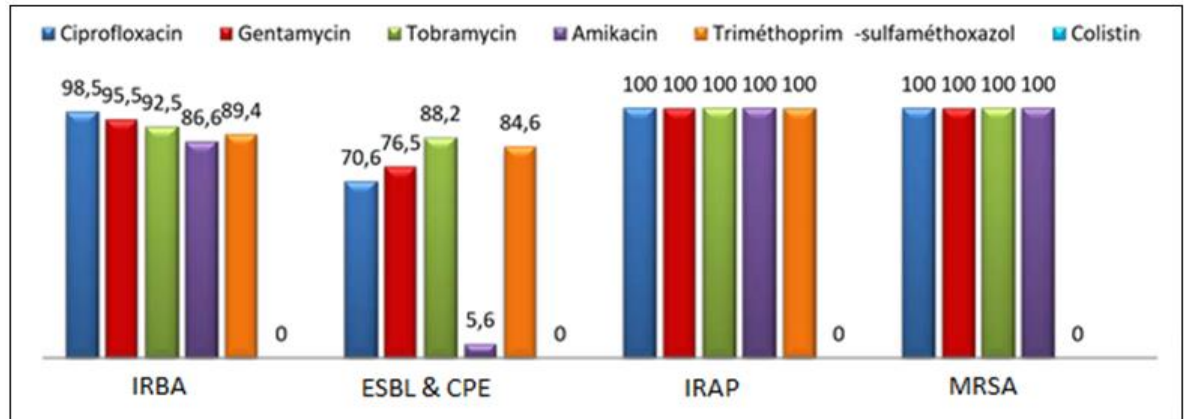

Figure 4: Co-resistance pattern of MRBs to other antibiotics (\%)

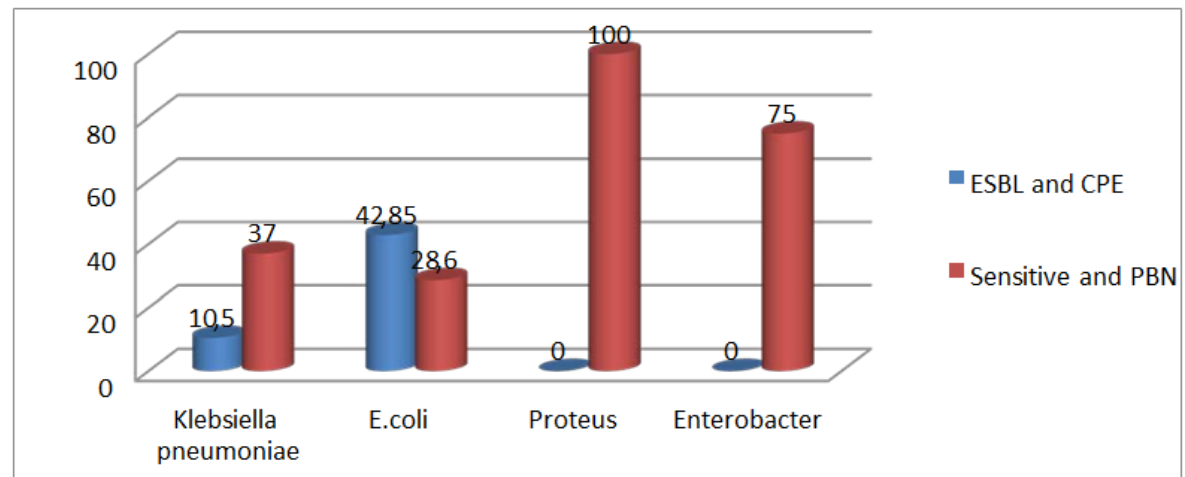

Figure 5: Distribution of Enterobacteriaceae by resistance level

2- Study of risk factors for the acquisition of MRB NPs

In our study, an extended analysis was performed on all epidemiological, clinical, paraclinical and therapeutic characteristics, in order to highlight the risk factors for the occurrence of MRB NPs (Table I and II).

Table I: Epidemiological and clinical risk factors studied in our work

\begin{tabular}{|l|l|l|}
\hline Epidemiological and clinical characteristics of patients & number of patients & $\%$ \\
\hline Age (years) & 11 & 18,3 \\
$26-35$ & 25 & 41,7 \\
$36-45$ & 11 & 18,3 \\
$46-55$ & 7 & 11,5 \\
$>56$ & 6 & 10 \\
\hline Sex & 51 & 83,6 \\
\hline Man & 10 & 16,4 \\
Woman & \multicolumn{2}{|l|}{} \\
\hline Reason for hospitalization & 22 & 36,1 \\
\hline Polytrauma & 22 & 36,1 \\
Severe cranial trauma & 5 & 8,2 \\
\hline Post operative &
\end{tabular}


I. Karrati et al; Sch J App Med Sci, Jan, 2022; 10(1): 72-78

\begin{tabular}{|l|l|l|}
\hline Epidemiological and clinical characteristics of patients & number of patients & $\%$ \\
\hline status epilepticus & 2 & 3,3 \\
Visceral pathology & 1 & 1,6 \\
Others & 9 & 14,8 \\
\hline Duration of hospitalization (days) & \multicolumn{2}{|l|}{} \\
\hline$<10$ & 16 & 26,2 \\
$10-20$ & 19 & 31,1 \\
\hline $20-30$ & 13 & 21,3 \\
$>30$ & 13 & 21,3 \\
\hline Nosocomial pneumonia & \multicolumn{2}{|l|}{} \\
\hline Early NP & 32 & 52,5 \\
Late NP & 29 & 47,5 \\
\hline Comorbidities & \multicolumn{2}{|l|}{} \\
\hline Yes & 9 & 14,8 \\
No & 52 & 14,8 \\
\hline Associated infection & 9 & 85,2 \\
\hline Yes & 52 & \\
No & \multicolumn{2}{|l|}{} \\
\hline
\end{tabular}

Table II: Therapeutic and evolutionary risk factors studied in our work:

\begin{tabular}{|c|c|c|c|}
\hline \multicolumn{2}{|c|}{ Therapeutic and evolutionary characteristics of patients } & Number of patients & $\%$ \\
\hline \multirow{2}{*}{ Gastric catheterisation } & yes & 61 & 100 \\
\hline & No & 0 & 0 \\
\hline \multirow[t]{2}{*}{ Urine catheterisation } & yes & 61 & 100 \\
\hline & No & 0 & 0 \\
\hline \multirow[t]{2}{*}{ Half sitting position } & yes & 61 & 100 \\
\hline & No & 0 & 0 \\
\hline \multirow[t]{2}{*}{ Central venous Catheter } & yes & 45 & 73,8 \\
\hline & No & 16 & 26,2 \\
\hline \multirow[t]{2}{*}{ Drainage } & yes & 3 & 4,9 \\
\hline & No & 58 & 95,1 \\
\hline \multirow[t]{2}{*}{ Tracheostomy } & yes & 6 & 9,8 \\
\hline & No & 55 & 90,2 \\
\hline \multirow[t]{2}{*}{ Re-intubation } & yes & 4 & 6,1 \\
\hline & No & 57 & 93,4 \\
\hline \multicolumn{4}{|l|}{ Clinical signs/para-clinical } \\
\hline \multirow{2}{*}{ Hypothermia } & Yes & 3 & 4,9 \\
\hline & No & 58 & 95,1 \\
\hline \multirow[t]{2}{*}{ Fever } & Yes & 45 & 73,8 \\
\hline & No & 16 & 26,2 \\
\hline \multirow[t]{2}{*}{ Purulent Secretions } & Yes & 26 & 42,6 \\
\hline & No & 35 & 57,4 \\
\hline \multirow{2}{*}{ Hyperleukocytosis } & Yes & 55 & 91,7 \\
\hline & No & 5 & 8,2 \\
\hline \multirow[t]{2}{*}{ Radiological image } & Yes & 46 & 75,4 \\
\hline & No & 15 & 24,6 \\
\hline \multirow[t]{2}{*}{ Probabilistic antibiotic therapy } & Administrated & 24 & 39,3 \\
\hline & No & 37 & 60,7 \\
\hline \multirow[t]{2}{*}{ Evolution } & Favourable & 22 & 36,1 \\
\hline & Unfavorable & 38 & 62,1 \\
\hline
\end{tabular}

Statistical analysis of the relationship between the different patient characteristics and the occurrence of nosocomial pneumonia with $1 \mathrm{MRB}$ (table III) and more than 2 MRBs (table IV) revealed multiple risk factors:

Table III: Risk factors found in the acquisition of a single BMR responsible for nosocomial pneumonia

\begin{tabular}{|l|l|l|l|}
\hline Characteristics of patients & value $\mathbf{P}$ & odds ratio & confidence interval 95\% \\
\hline Age 36-45 years & 0.05 & 0.766 & {$[0.654-0.897]$} \\
Fever & 0.015 & 0.667 & {$[0.546-0.814]$} \\
Radiological image & 0.001 & 9.371 & {$[2.369-37.069]$} \\
\hline
\end{tabular}


I. Karrati et al; Sch J App Med Sci, Jan, 2022; 10(1): 72-78

Table IV: Risk factors found in the acquisition of more than 2 MRBs responsible for nosocomial pneumonia

\begin{tabular}{|l|l|l|l|}
\hline Characteristics of patients & value P & odds ratio & confidence interval 95\% \\
\hline Age 36-45 years & 0.02 & 0.2 & {$[0.048-0.837]$} \\
Severe head injury & 0.026 & 8.25 & {$[0.986-68.998]$} \\
Other reasons for hospitalisation & 0.003 & 0.124 & {$[0.027-0.579]$} \\
Duration of stay between 10-20 days & 0.05 & 6.387 & {$[0.761-53.635]$} \\
Comorbidities & 0.04 & 2.146 & {$[0.242-19.04]$} \\
Radiological image & 0.027 & 0.694 & {$[0.576-0.836]$} \\
\hline
\end{tabular}

Thus, the study of the relationship between the characteristics of the patients and the occurrence of nosocomial pneumopathies caused by ABRI and enterobacteriaceae ESBL and/or EPC has made it possible to detect the following risk factors (table $\mathrm{V}$ and VI):

Table V: Risk factors found in the acquisition of IRBA responsible for nosocomial pneumonia

\begin{tabular}{|l|l|l|l|}
\hline Characteristics of patients & value P & odds ratio & confidence interval 95\% \\
\hline Comorbidities & 0.05 & 1.8 & {$[1.691-1.926]$} \\
Radiological image & 0.001 & 8.357 & {$[2.256-10.952]$} \\
Broad spectrum antibiotic therapy & 0.05 & 0.8 & {$[0.691-0.926]$} \\
\hline
\end{tabular}

Table VI: Risk factors for the acquisition of enterobacteriaceae ESBL and/or EPC causing nosocomial pneumonia

\begin{tabular}{|l|l|l|l|}
\hline Characteristics of patients & value P & Odds ratio & confidence interval 95\% \\
\hline age (years) & 0.05 & 1.306 & {$[1.115-1.52$} \\
\hline$<25$ & 0.003 & 7.371 & {$[1.763-30.822]$} \\
$36-45$ & 0.007 & 6.875 & {$[1.511-31.287]$} \\
\hline Other reasons for hospitalisation & 0.5 \\
\hline \multicolumn{4}{|l|}{ Duration of hospitalisation (days) } \\
\hline $10-20$ & 0.04 & 0.139 & {$[0.017-1.159]$} \\
$20-30$ & 0.014 & 5.020 & {$[1.297-19.430]$} \\
\hline
\end{tabular}

\section{Discussion}

In the results of our work, the percentage of ABRI in relation to all MRBs was the highest and constituted $75 \%$ of BMR. Some publications in this sense report a rate even lower than $10 \%$. For MRSA and IRAP, the figures from foreign studies are more worrying based on the overall percentages of isolation of the two types of bacteria.
The rate of multidrug resistance of Enterobacteriaceae was in the vicinity of the other literature. ESBL enterobacteria represent the most dominant group. Only one study reported CPE enterobacteria more frequently. Klebsiella pneumonia was the most incriminated bacterium in the occurrence of MDR-Enterobacteria NPs in our work as well as the other studies consulted (Table VII).

\begin{tabular}{|c|c|c|c|c|c|c|c|c|c|c|c|c|c|c|}
\hline \multirow{3}{*}{$\begin{array}{l}\text { The author of the } \\
\text { study (year) }\end{array}$} & \multirow{3}{*}{ Country } & \multicolumn{12}{|c|}{ Table VII: Distribution of MRBs } & \multirow[b]{3}{*}{$\begin{array}{l}\% \\
\text { E.C }\end{array}$} \\
\hline & & \multirow{2}{*}{$\begin{array}{l}\text { Rate } \\
\text { of } \\
\text { MRB }\end{array}$} & \multicolumn{2}{|c|}{ IRBA } & \multicolumn{2}{|c|}{ IRAP } & \multicolumn{2}{|c|}{ MRSA } & \multirow[b]{2}{*}{$\% a$} & \multicolumn{4}{|c|}{ Enterobacteriaceae MRB } & \\
\hline & & & $\% \mathbf{a}$ & $\% \mathbf{b}$ & $\% \mathbf{a}$ & $\% \mathrm{~b}$ & $\% \mathbf{a}$ & $\% \mathbf{b}$ & & $\% b$ & $\begin{array}{l}\% \\
\text { ESBL }\end{array}$ & $\begin{array}{c}\% \\
\text { CPE }\end{array}$ & $\begin{array}{l}\% \\
\text { K.P }\end{array}$ & \\
\hline $\begin{array}{l}\text { Azzab et al., (2016) } \\
\text { [2] }\end{array}$ & Egypte & 82,6 & 9,8 & 87,5 & 16,9 & 92,3 & 16,9 & 80 & 52,1 & 88 & 30 & 70 & 94,5 & 5,5 \\
\hline $\begin{array}{l}\text { Soubirou et al., } \\
\text { (2014) [3] }\end{array}$ & France & 60,4 & 0,8 & 20 & 12 & 36,8 & 0,8 & 5,5 & 48,3 & 65,9 & 35,7 & 64,3 & - & - \\
\hline $\begin{array}{l}\text { Tedja et al., (2014) } \\
\text { [4] }\end{array}$ & Etats unis & 45,8 & 26,5 & 92,8 & 26,5 & 37,1 & 8,2 & 33,3 & 6,12 & 18,8 & - & - & - & - \\
\hline $\begin{array}{l}\text { Mathai et al., } \\
\text { (2015) [5] }\end{array}$ & Inde & 53,6 & 42,4 & 43,1 & 6,77 & 28 & 0 & 0 & 50,8 & 69,7 & 60 & 40 & 83,3 & 16,7 \\
\hline $\begin{array}{l}\text { Souza Oliveira } e t \\
\text { al., (2016) [6] }\end{array}$ & Brésil & 46,7 & 29 & 69,2 & 32,2 & 47,6 & 17,7 & 36,6 & 17,7 & 42,3 & 100 & 0 & 45,5 & 9 \\
\hline $\begin{array}{l}\text { Vasudevan et al., } \\
\text { (2013) [7] }\end{array}$ & Singapoure & 34 & 34,4 & 77,3 & 13,4 & 25,4 & 37,8 & 57,7 & 14,3 & 19,3 & - & - & 88 & 12 \\
\hline $\begin{array}{l}\text { Werarak et al., } \\
\text { (2010) [8] }\end{array}$ & Thaïlande & 66,3 & 6,8 & 8,9 & 52 & 80,8 & 8,2 & 42,8 & 32,9 & 80 & 100 & 0 & 87,5 & 12,5 \\
\hline $\begin{array}{l}\text { Lalaoui S. (2016) } \\
\text { [9] }\end{array}$ & Maroc & 47,4 & 69,8 & 72,8 & 4,1 & 25 & 6,8 & 25 & 19,1 & 43,7 & 78,5 & 31,5 & 72,7 & 9,1 \\
\hline Our study & Maroc & 38 & 75 & 95,6 & 1 & 5,2 & 2 & 4 & 22 & 25 & 79 & 21 & 48 & 21 \\
\hline
\end{tabular}

a: percentage of MRBs of the species compared to all BMRs

b: percentage of MRBs of the species compared to all strains of the species 
I. Karrati et al; Sch J App Med Sci, Jan, 2022; 10(1): 72-78

In our study, the risk factors found to play a role in the acquisition of NPs with 2 or more MRBs were: an advanced age compared to the average in our series, between 36 and 45 years, a length of hospitalisation between 10 and 20 days, the presence of a comorbidity (hypertension, diabetes, toxic pathology), and a radiological image highly suggestive of NPs. While the risk factors found for NP at ABRI were the presence of a comorbidity, a radiological image highly suggestive of NP and broad-spectrum antibiotic therapy.

A retrospective study published in 2014 conducted in France over 30 months to assess the influence and spread of multidrug-resistant BGN, especially carbapenem-resistant BGN, identified prolonged length of stay in the ICU before resorting to ventilation, prolonged duration of mechanical ventilation, and use of broad-spectrum antibiotic therapy for a long period of time as risk factors for acquiring multidrug-resistant BGN NPs [10].

A US study published in 2014 conducted over 3 years on the impact of multidrug resistance of antibiotics on NPs identified length of hospital stay prior to ventilation use and home use of antibiotics 30 days prior to admission as risk factors for MRBs [11].

A similar study in Belgium in 2008 found several factors that modify the occurrence of $\mathrm{FN}$ with BMRs: advanced age, acute respiratory distress syndrome and coma as reasons for ICU hospitalisation, length of ICU hospitalisation and exposure to more than 2 classes of antibiotics before NP [12].

A study done in Spain published in 2014 reported as risk factors for acquisition of BMRs responsible for NPs: nosocomial infection associated with bacteremia type, reintubation, tracheotomy and recurrence of NP [13].

In South Korea, a study on risk factors for NPs caused by carbapenem-resistant BGNs revealed diabetes mellitus and neurological diseases as agents influencing the acquisition of this type of bacteria [14].

A recent study published in 2017 in Japan on the PES group (Pseudomonas aeruginosa, enterobacteriaceae ESBL and MRSA) showed that male sex, smoking, history of DDB, discharge from hospital within the first 30 days and enteral feeding are factors favouring PN to this germ type [15].

A study in India published in 2008 on the role of BMRs in NPs identified hospitalisation >5 days, prior antibiotic therapy, altered consciousness, neurological disorder, surgery and use of corticosteroids as risk factors for MRB NPs [16].
In a study conducted in Turkey in 2014 about highly resistant Acinetobacter baumannii NPs revealed length of hospitalization in ICU and length of hospital stay as risk factors [17].

\section{CONCLUSION}

Our results, and in accordance with the literature, showed the important prevalence of BMR in nosocomial pneumonia as well as high levels of resistance to the different families of antibiotics useful for the treatment of these infections and constitute for some molecules the last resort in bacterial therapy. This study also reported a predominance of ABRI and a significant decrease in MRSA and IRAP.

These phenomena make multiresistance to antibiotics a truly worrying and alarming problem because of the potential risks (therapeutic impasse, increased morbidity and mortality, additional economic costs and installation of highly resistant bacteria in hospital services).

The microbiological study of bronchial samples should be used to adapt antibiotic therapy and not be limited to diagnosis. The pitfall of empirical use of antibiotics for suspected NP is the potential for antibiotic overuse, emergence of resistance, unnecessary adverse effects and potential toxicity. The main objectives of the management of NP should be: early initiation, appropriate antibiotics with adequate doses followed by de-escalation based on microbiological culture results and the patient's clinical response.

\section{REFERENCES}

1. Girault, C., Tamion, F., \& Beduneau, G. (2006). Évaluation des soins et pneumopathies nosocomiales en réanimation. Revue des maladies respiratoires, 23(2), 27-43.

2. Azzab, M. M., El Sokkary, R. H., Tawfeek, M. M., \& Gebriel, M. G. (2016). Multidrug-resistant bacteria among patients with ventilator-associated pneumonia in an emergency intensive care unit, Egypt. EMHJ-Eastern Mediterranean Health Journal, 22(12), 894-903.

3. Soubirou, J. F., Gault, N., Alfaiate, T., Lolom, I., Tubach, F., Andremont, A., ... \& Barbier, F. (2014). Ventilator-associated pneumonia due to carbapenem-resistant Gram-negative bacilli in an intensive care unit without carbapenemaseproducing Enterobacteriaceae or epidemic Acinetobacter baumannii. Scandinavian journal of infectious diseases, 46(3), 215-220.

4. Tedja, R., Nowacki, A., Fraser, T., Fatica, C., Griffiths, L., Gordon, S., ... \& van Duin, D. (2014). The impact of multidrug resistance on outcomes in ventilator-associated pneumonia. American journal of infection control, 42(5), 542-545. 
5. Mathai, A. S., Phillips, A., Kaur, P., \& Isaac, R. (2015). Incidence and attributable costs of ventilator-associated pneumonia (VAP) in a tertiary-level intensive care unit (ICU) in northern India. Journal of infection and public health, 8(2), 127-135.

6. Souza-Oliveira, A. C., Cunha, T. M., Passos, L. B. D. S., Lopes, G. C., Gomes, F. A., \& Röder, D. V. D. D. B. (2016). Ventilator-associated pneumonia: the influence of bacterial resistance, prescription errors, and de-escalation of antimicrobial therapy on mortality rates. Brazilian Journal of Infectious Diseases, 20, 437-443.

7. Vasudevan, A., Chuang, L., Jialiang, L., Mukhopadhyay, A., Goh, E. Y. Y., \& Tambyah, P. A. (2013). Inappropriate empirical antimicrobial therapy for multidrug-resistant organisms in critically ill patients with pneumonia is not an independent risk factor for mortality: results of a prospective observational study of 758 patients. Journal of global antimicrobial resistance, 1(3), 123-130.

8. Werarak, P., Kiratisin, P., \& Thamlikitkul, V. (2010). Hospital-acquired pneumonia and ventilator-associated pneumonia in adults at Siriraj Hospital: etiology, clinical outcomes, and impact of antimicrobial resistance. J Med Assoc Thai, 93(Suppl 1), S126-138.

9. Lalaoui, S. (2016). Profil bactériologique des pneumopathies nosocomiales de l'adulte et état de résistance aux antibiotiques. Thèse de médecine Marrakech 2016, $\mathrm{N}^{\circ} 122$.

10. Soubirou, J. F., Gault, N., Alfaiate, T., Lolom, I., Tubach, F., Andremont, A., ... \& Barbier, F. (2014). Ventilator-associated pneumonia due to carbapenem-resistant Gram-negative bacilli in an intensive care unit without carbapenemaseproducing Enterobacteriaceae or epidemic Acinetobacter baumannii. Scandinavian journal of infectious diseases, 46(3), 215-220.

11. Tedja, R., Nowacki, A., Fraser, T., Fatica, C., Griffiths, L., Gordon, S., ... \& van Duin, D. (2014). The impact of multidrug resistance on outcomes in ventilator-associated pneumonia. American journal of infection control, 42(5), 542-545.

12. Depuydt, P. O., Vandijck, D. M., Bekaert, M. A., Decruyenaere, J. M., Blot, S. I., Vogelaers, D. P., \& Benoit, D. D. (2008). Determinants and impact of multidrug antibiotic resistance in pathogens causing ventilator-associated-pneumonia. Critical Care, 12(6), 1-10.

13. Martin-Loeches, I., Torres, A., Rinaudo, M., Terraneo, S., de Rosa, F., Ramirez, P., ... \& Ferrer, M. (2015). Resistance patterns and outcomes in intensive care unit (ICU)-acquired pneumonia. Validation of European Centre for Disease Prevention and Control (ECDC) and the Centers for Disease Control and Prevention (CDC) classification of multidrug resistant organisms. Journal of Infection, 70(3), 213-222.

14. Kim, T., Chong, Y. P., Park, S. Y., Jeon, M. H., Choo, E. J., Chung, J. W., ... \& Kim, Y. S. (2014). Risk factors for hospital-acquired pneumonia caused by carbapenem-resistant Gram-negative bacteria in critically ill patients: a multicenter study in Korea. Diagnostic Microbiology and Infectious Disease, 78(4), 457-461.

15. Ishida, T., Ito, A., Washio, Y., Yamazaki, A., Noyama, M., Tokioka, F., \& Arita, M. (2017). Risk factors for drug-resistant pathogens in immunocompetent patients with pneumonia: evaluation of PES pathogens. Journal of Infection and Chemotherapy, 23(1), 23-28.

16. Joseph, N. M., Sistla, S., Dutta, T. K., Badhe, A. S., Rasitha, D., \& Parija, S. C. (2010). Ventilatorassociated pneumonia in a tertiary care hospital in India: role of multi-drug resistant pathogens. The Journal of Infection in Developing Countries, 4(04), 218-225.

17. Özgür, E. S., Horasan, E. S., Karaca, K., Ersöz, G., Atış, S. N., \& Kaya, A. (2014). Ventilatorassociated pneumonia due to extensive drugresistant Acinetobacter baumannii: risk factors, clinical features, and outcomes. American journal of infection control, 42(2), 206-208. 